\title{
On-Street Visual Analysis on Jalan Hang Jebat, Melaka
}

\section{Zalina Samadi, Dasimah Omar, Rodzyah Mohd Yunus}

\author{
Faculty of Architecture, Planning and Surveying, \\ Universiti Teknologi MARA, Shah Alam, Selangor, Malaysia \\ zalina_samadi@yahoo.com
}

\begin{abstract}
Outdoor space in between heritage buildings of heritage streets defines as 'outdoor living room'. Whether it's impressively 'heritage' or 'commercially' character; physical and socio-cultural characteristics of the streets have great influence towards eliciting on-street pedestrian model. The purpose of this study is to determine the relationship between timeframe and density, activity and movement based on the on-street cultural phenomenon. For the purpose of this paper, the presentation unveiled one section of the study which shares the analysis on-street's aerial-visual data only. Unobtrusive methods were employed through Digital Photography and Closed Circuit Television (CCTV) at Jalan Hang Jebat, Melaka. The objectives of this study are to interpret density, activity and movement analysis.
\end{abstract}

Keywords: Outstanding value; outdoor living room; pedestrian pattern; street shopping

eISSN 2514-751X @ 2018. The Authors. Published for AMER ABRA cE-Bs by e-International Publishing House, Ltd., UK. This is an open-access article under the CC BY-NC-ND license (http://creativecommons.org/licenses/by$n c-n d / 4.0 /$ ). Peer-review under responsibility of AMER (Association of Malaysian Environment-Behaviour Researchers), ABRA (Association of Behavioural Researchers on Asians) and $c E-B s$ (Centre for EnvironmentBehaviour Studies), Faculty of Architecture, Planning \& Surveying, Universiti Teknologi MARA, Malaysia.

DOI: https://doi.org/10.21834/aje-bs.v3i9.27 


\subsection{Introduction}

The direct relationship between pedestrian movements and on-street activity to revitalize a positive aura within a heritage outdoor space may be fully not understood, but further studies on heritage street's therapeutic attributes with pedestrian prove that indulging in creative activities such as outdoor street shopping often decreases solemnity and increases livability. However, the relationship between pedestrian movement and activity can be analyzed fully through a number of methods including Digital Photography Analysis or Close Circuit Television (CCTV) which records street's activities. The current research on evaluating urban outdoor space quality indicated that both manual and technological application is applied as complimentary methods. Understanding the high value of revitalization that has positive aura's enhancement within a heritage outdoor space has sparkle the responsible city authority known as Majlis Bandaraya Melaka Bersejarah (MBMB) to joint-venture with the lbu Pejabat Kontinjen Polis, Melaka Tengah (IPK, Melaka Tengah).

The form of data collected is in the form of video motion and non motion detection. From time to time, all collected video camera input data is kept for record purpose in case of any crime and accident scene in the area. Jalan Hang Jebat is accepted by public as one of the most vibrant streets within the heritage core zone with least crime area. Therefore, this juxtaposition has elevated this street with added value as a unique identity: 'vibrant but secure street'. Due to this uniqueness of high revitalization with peaceful street yet maintains its vibrancy makes the street a real attractive street. No doubt, this street has its own outstanding value on top of the outstanding universal value as established in UNESCO World Heritage Sites in 2008.

\subsection{Outstanding Value}

Outstanding universal value of Melaka is on her 'multi-culturalism' quality which rarely found to the world. The architectural style of its built heritage is demonstrated in the historical shop houses. The cultural heritage is demonstrated through the continuous trading lifestyle as previous port city activity from the sub-cultures from Asian such as India, China, Malay and other continent such as Europe. There are mainly three most Outstanding Universal Values as recorded by Cultural Heritage Action Theme (CHAT) of Penang:

- First Outstanding Universal Value: the Multi-trading town as forged from exchanges of cultures

- Second Outstanding Universal Value: a Living Testimony of Tangible and Intangible Heritage

- Third Outstanding Universal Value: the Melting Pot of Multicultural Architecture and Township

The similar value and built heritage of early shop houses can also be found in Melaka. The similarity image and identity between Penang and Melaka shop houses are due to the identical social influences of the heritage cities of the Straits of Malacca with spice up with architecture from the British Colonial, European, Asian and multi-ethnic influences. 


\subsection{Outdoor Living Room}

R. Robertson (1992) in the particularization within the globalization age stated dictated that globalization has its own richness such as particularization of local tourism activity empowerment to attract global tourism. For instance, to consume World Heritage Sites physically tourists can only access the physical elements such as the architecture or the interior in the indoor and the outdoor space of the sites. The activities that tourists may do are visiting galleries, shopping, eating and heritage walking. In this research, outdoor living room refers the outdoor public space in between heritage streets with designed to provide tourist basic amenity while they are off their accommodation. An appropriate outdoor living room provides street furniture which is design for all. The furniture shall be made up of resilience material, robust and flexible quality to cater universal tourism. (Evans, 2009) promotes creative spaces in revitalizing urban area by all means of design principles to reduce unintended area and reduce the crime-prone area. (Edwards, Griffin \& Hayllar, 2008) identified weakness on the lack of integration of spaces among practitioners, researchers and policy maker. This is the one of the threats of a livable heritage city which caused underutilized and negative space in the urban area. The space shall be focused for urban recreation activities rather than left as unintended and no man's land (Samadi, $Z$ and Hasbullah, M.N., 2008).

\subsection{Pedestrian Pattern}

The research on pedestrian pattern and intensity were cross examined by many city legibility researchers. Stefan, S. (2006) described that the accuracy of application of Geo-Positioning System (GPS) until the millennium era was limited up to thirty meters from the ground due to international military safety restriction. Due to that limitation and satellite's accessibility restriction to obtain data from the authority has lead the research conduct to have on-street pedestrian observation to record pedestrian pattern. At this level, human eye level's has its advantageous in terms of visualising the outdoor environment, the density of pedestrian and the on-street activity. The daily operation for the indoor shopping activity in the heritage shop houses of Jalan Hang Jebat begins in between nine o'clock in the morning to ten o'clock at night. From Friday to Sunday, the business activity in the shop houses closed at seven o'clock in the evening to allow Night Market to operate until midnight. This activity attracts overflows of pedestrian for on-street shopping and dining. This night market has attracted local and international tourists. Some of them simply come to enjoy shopping and join the crowd to feel the vibrant environment. The character of the street is supported by pedestrian flow from the nearby heritage tourism activity where visitors come to visit historical monuments in Bandar Hilir such as A Famosa, Stadhuy's, Museum of Malacca and Melaka Night Cruise.

\subsection{Heritage Streets Shopping}

Street Shopping is the main activities in Jalan Hang Jebat. Besides that, due to local communities demand on public entertainment for the elderly who stayed at the surrounding area the heritage street provides an open air outdoor stage with minus-one equipment for performance. The location of this open air stage was towards the end of Jalan Hang Jebat 
heading to Jalan Kubu. This performer is for fun but it has attracted more street shoppers to visit and access live and joyful ambiance to create richness experience.

\subsection{Aerial-Visual}

According to Thomas, A. and Gevanthor, A. (2007) defined that aerial as originated in early $17^{\text {th }}$ century from Latin called "aerius" and from Greek called "aerios". It is the most common, versatile and economical form of remote sensing. This paper only shares the digital camera version. Prior to the research conduct, researchers logged in a report to the police department for ensuring their presence on-street were under the protection by the police.

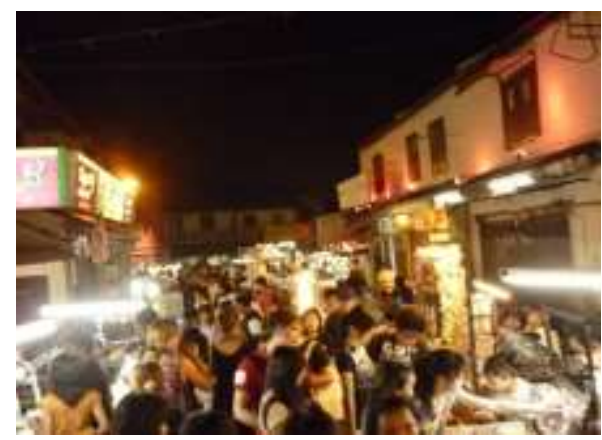

Figure 1: Night market view shopping along Jalan Hang Jebat

\subsection{Methodology}

\subsection{Participation, Ethics and Procedures for CCTV}

This research was conducted in between March 2012 to August 2012 with two non-obtrusive measures; Digital Photography Analysis and CCTV Analysis. However, the interpretation in the research does not achieve the level of forensic CCTV Video Analysis as offered by Forensic Resources Ltd (2009). In terms of research participation, CCTV does not involve end-users direct involvement except for recording their routine behavior in the real phenomenon on the street. The application of CCTV video camera is typically used to capture and record the event of any suspicious circumstances and recall event to a non broadcast transmission system.

The police department together with MBMB set the CCTV at the selected points. The exact positioning of the equipment was identified in ensuring public safety and function as part of crime reduction measures for maintaining high quality safety and surveillance. The CCTV setting in the heritage street is part of the precaution to detect and provide useful information on end users behavioral patterns. This research does not require as direct participation but end-users were observed in terms of their movement pattern, behavior and intensity from the CCTV only. However, due to the limitation of view there is a space which is located as hidden 
spot. The researcher required to grant written permission as the ethical procedure from the Head of Police Contingent at Bukit Beruang prior to the CCTV assessment.

\subsection{Aerial-Visual Assessment Criteria (Avac): Research Design and Data Log Sheet}

This research employ unobtrusive-data collection with on-street manual calculation was recorded for calculating on street intensity of end-users passing and shopping along the study street. This manual calculation on site was counter checked again from digital photography and CCTV for validating the result. However, due to non-synchronized in terms of time for collecting the end-users' intensity considered as common error since the conduct of this research was done individually. Similar with the digital camera; the data collected from the CCTV's real-time of video camera data collection also not synchronized as the same time as manually collection. The following figures representing samples of digital photography used for on-site data for analysis in calculating density of street during night market. However, the CCTV data is strictly confidential and limitedly for viewing. This paper only share the AerialVisual Assessment (AVA) used for the analysis on the provided data.

\begin{tabular}{lllll}
\multicolumn{6}{c}{ Table 1: Sample of A4-sized data log sheet of the Aerial-Visual } & Assessment (AVA) \\
\hline Timeline & $\begin{array}{l}\text { Duration } \\
\text { (6 Option) }\end{array}$ & $\begin{array}{l}\text { Type of } \\
\text { Activity } \\
\text { (3 options) }\end{array}$ & $\begin{array}{l}\text { Intensity of } \\
\text { people } \\
\text { 10 sq ft area } \\
\text { (4 options) }\end{array}$ & $\begin{array}{l}\text { Movement } \\
\text { (3 options) }\end{array}$ \\
\hline Morning & $0800-1200$ & Indoor & $1-5$ & Direct and one \\
Afternoon & $1200-1600$ & Shopping & $6-10$ & way only \\
Evening & $1600-2000$ & Indoor & $11-15$ & Meandering \\
Early Night & $2000-2400$ & \&Outdoor & $20-30$ & and to and \\
Midnight & $2400-0400$ & On-street & & from shopping \\
Night & $1800-2400$ & shopping & & outlet \\
Market & & & Meandering \\
& & & Active \\
\hline
\end{tabular}

\subsection{Result And Discussion}

\subsection{Activity along Jalan Hang Jebat}

Based on the data collection in March 2012 to October 2012, there are three main activities in Jalan Hang Jebat. The first activity is Indoor Shopping which is lineage along the heritage shop houses. The second activity is Indoor and Outdoor Shopping and the third one is OnStreet Shopping. The activity is observed as varies along the daytime and night-time line as shown in the following table. 
Table 2: Activity along Jalan Hang Jebat

\begin{tabular}{llll}
\hline Timeline & Duration & Type of Activity & $\begin{array}{l}\text { \% of } \\
\text { Frequency }\end{array}$ \\
\hline Morning & $0800-1200$ & Indoor Shopping & 11.40 \\
Afternoon & $1200-1600$ & Indoor Shopping & 22.00 \\
Evening & $1600-2000$ & Indoor \& Outdoor & 18.00 \\
Early Night & $2000-2400$ & Indoor \& Outdoor & 30.10 \\
Midnight & $2400-0400$ & Indoor \& Outdoor & 2.00 \\
Friday to Sunday & $1800-2400$ & On-street shopping & 16.50 \\
[Night Market] & & & \\
Total & & & 100.00 \\
\hline
\end{tabular}

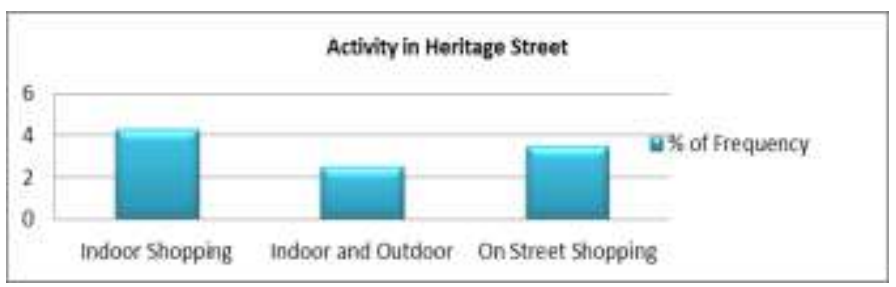

Figure 2: Selected type of activity by pedestrian

\subsection{Intensity of End Users Including Visitors, Shop Owners and Street Vendors}

The first one is as Low Distributed Pattern (LDP) with a number of pedestrian with intensity between $1-5$ person in 10 square meter area as detected early in the morning, afternoon and evening along the walkway of the study street. Pedestrian passing by to their work place and tourist also found for site seeing. This is due to the vehicular traffic is open for accessibility for both directions that limit pedestrian to walk on the street. The second is the Average Distribution Pattern (ADP) with the rate of the pedestrian is between 6-10 end users in 10 square meter area which pedestrian pass by in between peak time. The third one is the High Distribution Pattern (HDP) rate of pedestrian intensity of 20-30 end-users in 10 square meter area during the evening to mid-night.

Table 3: Intensity of pedestrian at Jalan Hang Jebat

\begin{tabular}{llll}
\hline Timeline & Duration & $\begin{array}{l}\text { Intensity of End } \\
\text { User in 10 square } \\
\text { meter area }\end{array}$ & $\begin{array}{l}\% \text { of } \\
\text { Frequency }\end{array}$ \\
\hline Morning & $0800-1200$ & $1-5$ & 8.00 \\
Afternoon & $1200-1600$ & $6-10$ & 25.00 \\
Evening & $1600-2000$ & $11-15$ & 12.00 \\
Early Night & $2000-2400$ & $11-15$ & 13.00 \\
Midnight & $2400-0400$ & $1-5$ & 17.00 \\
Friday to Sunday [Night & $1800-2400$ & $20-30$ & 25.00 \\
Market] & & & $100.00 \%$ \\
$\quad$ Total & & & \\
\hline
\end{tabular}




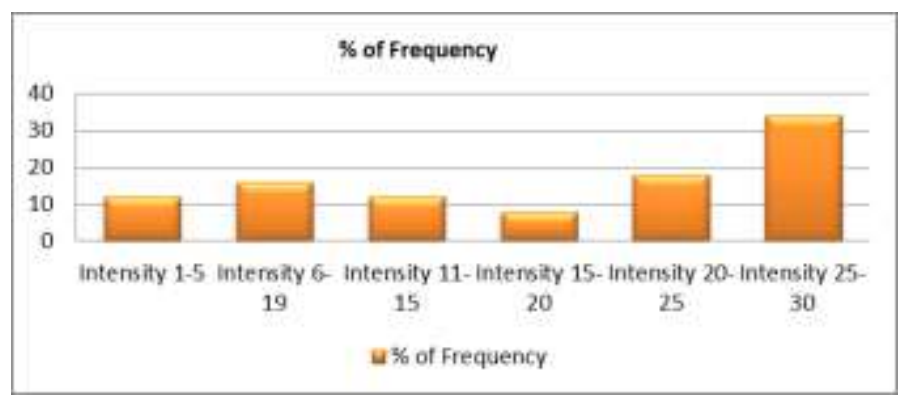

Figure 3: Result of pedestrian intensity

\subsection{Pedestrian Movement Pattern of Linear Linkages}

Table 4: Pedestrian movement at Jalan Hang Jebat

\begin{tabular}{llll}
\hline Timeline & Duration & $\begin{array}{l}\text { Pedestrian } \\
\text { Movement }\end{array}$ & \% of Frequency \\
& & Direct and one way & 12 \\
\hline Morning & $0800-1200$ & To and fro shopping & 10 \\
Afternoon & $1200-1600$ & To and fro shopping & 18 \\
Evening & $1600-2000$ & & \\
& & & 22 \\
Early Night & $2000-2400$ & To and fro shopping & 20 \\
Midnight & $2400-0400$ & Direct and one way & 18 \\
Friday to & $1800-2400$ & Meandering and active & \\
Sunday [Night & & & $100.00 \%$ \\
Market] & & & \\
Total & & & \\
\hline
\end{tabular}

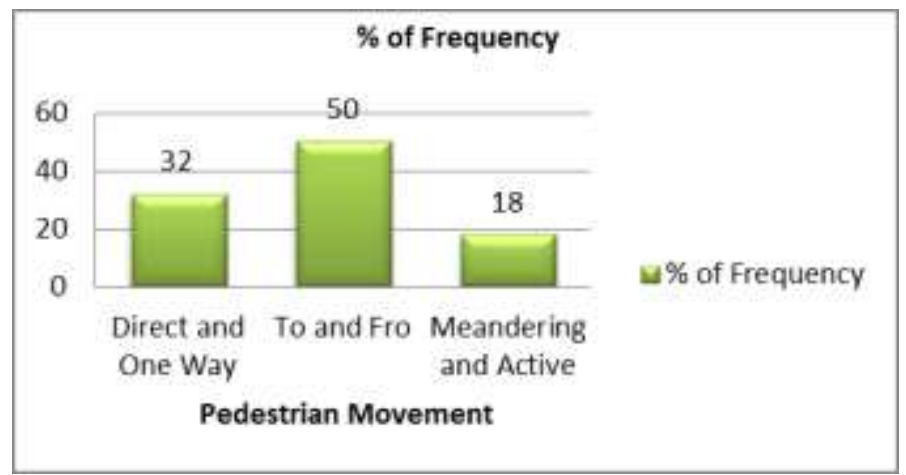

Figure 4: Result of Pedestrian Movement's Preference 
The existing pattern of pedestrian movement pattern has created a very strong linear linkage along Jalan Hang Jebat. The pattern varies along the 24 hours during the weekdays. During research conduct and data collection period which took about six months duration, it is observed that there were three main patterns in this street which varies from peak hour to low peak pattern can be detected in this street. Most of the pedestrian along this street are shop owners, vendors, local and international tourists and tourist guides who are very familiar with the tourism culture.

\subsection{Conclusion}

The empowerment shop owners and street vendors in Jalan Hang Jebat in managing the heritage street caused a great impact towards the revitalization of the street. Even though the encouragement from the local authority through physical enhancement of shop houses provided initiatives for street improvement but the employed data analysis have proved that livability and vibrancy of activity of the outdoor living room is highly depending on the pedestrian intensity. By having this study, hopefully it helps on improving the pedestrian movement management in heritage streets in Melaka.

\section{Acknowledgment}

The author wishes to dedicate special acknowledgement to the Melaka Central Police Headquarters for their approval for current and future assessment of the CCTV which was granted in May 2012. Unforgettable acknowledgement dedicated to Datuk Wira Gan Boon Leong due to his kind corporation from his residency/office at Jalan Kubu Melaka during data collection in conducting this research.

\section{References}

B. Yuen. (2005). Searching for Place Identity in Singapore. Habitat International, 29(2), 194-214.

Edwards, D., Griffin, T., \& Hayllar, B. (2008). Urban Tourism Research. Annals of Tourism Research, 35(4).

Evans, G. (2009). Creative Cities, Creative Spaces and Urban Policy. Urban Studies, 46(5-6).

Inc Icon Group International (Ed.) (2008). Revitalizing. Icon Group International.

Ramati, R., \& New York (N Y ) Dept of Planning Urban Design Group (Ed.) (1981). How to save your own street.

Roland, Robertson (1992). Globalization: Social Theory and Global Culture (Theory, Culture \& Society Series). SAGE Publication Limited, London.

Rubenstein, H. M. (Ed.) (1992). Pedestrian malls, streetscapes, and urban spaces. John Wiley \& Sons Inc.

Samadi, Z \& Hasbullah. M.N. (2008). The Enhancement of Space in between Urban Recreation Development. Online Refereed Journal of Malysian Publication. http: //www. malaysianpublications.blogsport. com/ 
Samadi, Z. \& Mohd Yunus, R.et.al. (2012). Conflict of Image and Identity on Heritage Commercialization. Elsevier: Science Direct Conference Procedia- Environmental Behaviour, 50, 674-684.

Samadi, Z. \& Mohd Yunus, R. (2012).Urban Heritage Streets' Revitalizing Attributes. Asian Journal of Environmental Behavioural Studies (AJEBs), 3(7), January 2012.

Shamsuddin, S. et.al. (2012). Walkable Environment in Increasing The Livability Of A City. Elsevier: Science Direct Conference Procedia- Environmental Behaviour.

Shamsuddin, S., Sulaiman, A.B. \& Che Amat., R. (2012). Urban Landscape Factors That Influenced the Character of George Town, Penang UNESCO World Heritage Site. Elsevier: Science Direct Conference ProcediaEnvironmental Behaviour.

Spek. Stefan Cristiaan Ven Der (2006). Legible City-Walkable City_ Livable City: Observation of walking pattern in City. Proceedings of the $7^{\text {th }}$ International Conference of Walking and Livable Communities, October 23-25, 2006 Taylor, L., \& Museum, C. H. (Ed.) (1981). Urban open spaces. Rizzoli Intl Pubns.

Zacharias. J. (2001). Pedestrian Behaviour and Perception in Urban Walking Environment. Journal of Planning Literature, 16(1). 